\title{
الصورة المعيارية للمجتمع القطري: دراسة في تصورات المقيمين

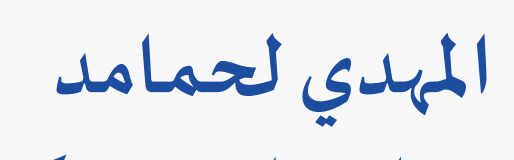

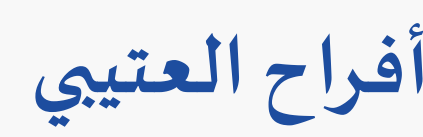

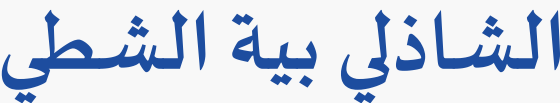 \\ أسماء حسين ملكاوي

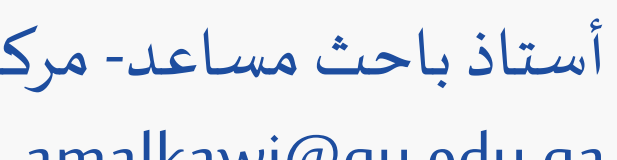

Faculty and PostDoc, Social Sciences and Humanities

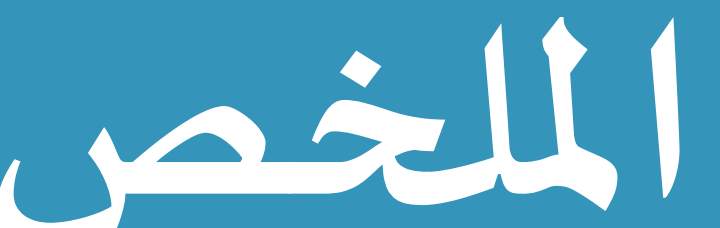

تهدف الدراسة إلى فهم تصيورات المقيمين تجاه

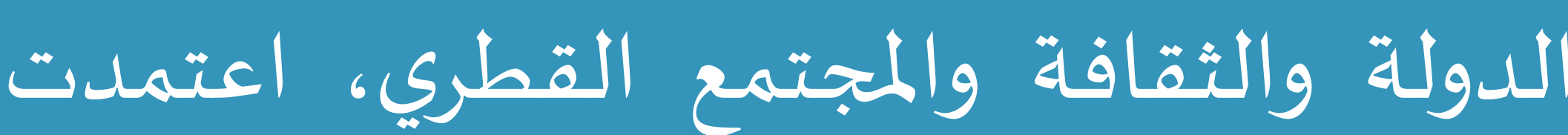

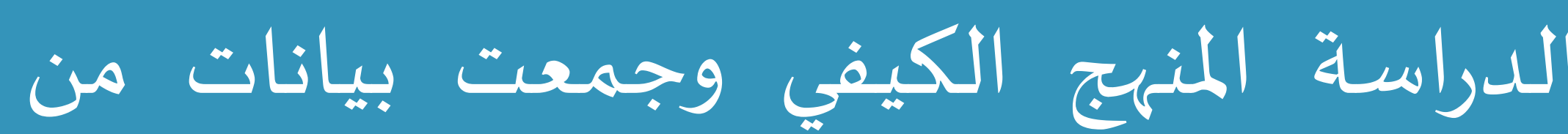

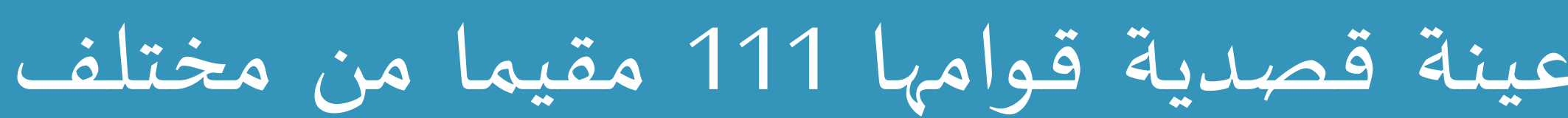
الجنسيات، أجري تحليل موضيوعاتي باستخدام MAXQDA. وخلصت الدراسة إلى إسئي أن لدولة قطر ميزات ثقافية إيجابية وبعضيها سلبية، إلا أن تصورات المقيمين في مجملها لهينا إيجابية تُجاهها، وتَخضيع لشروط؛ الخبان الخبرة الشخصية، والأطر المرجعية الثقافية. وتبعًا للمقيمين، فإن قطر سوف تواجه تحديات ثقافية أبرزها يرتبط باستحقاقات تتعارض مع إنعان الثقافة المحلية والمعتقدات الدينية، وأخرى ذات طابع حقوقي. تتمثل قيمة هذا البحث في

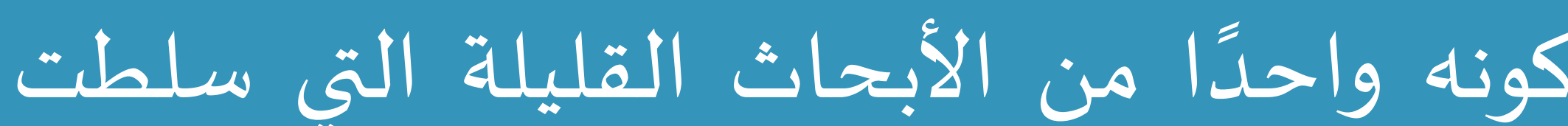

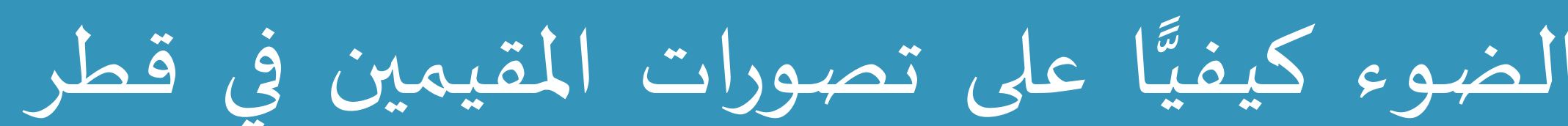
حول المجتمع والثقافة والشخصية القطرية في

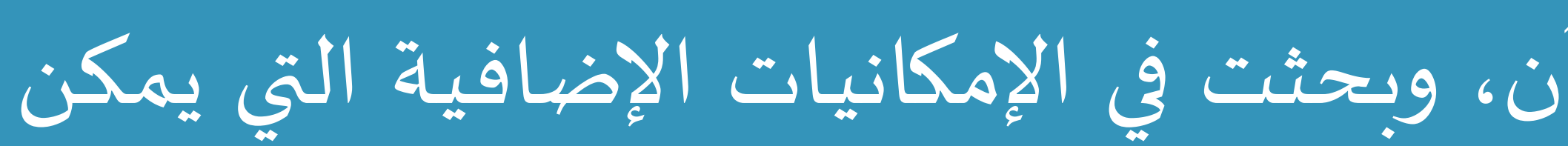

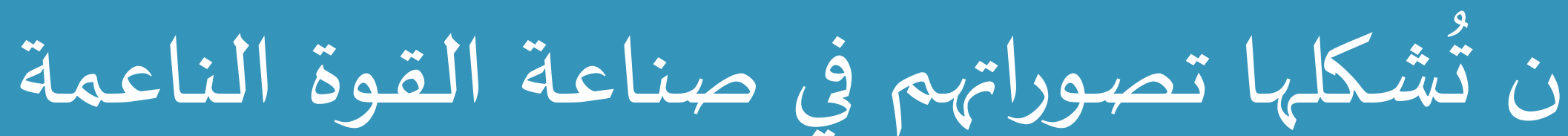

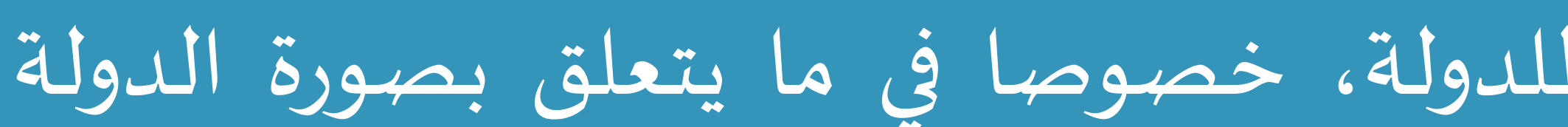
والترويج لها.

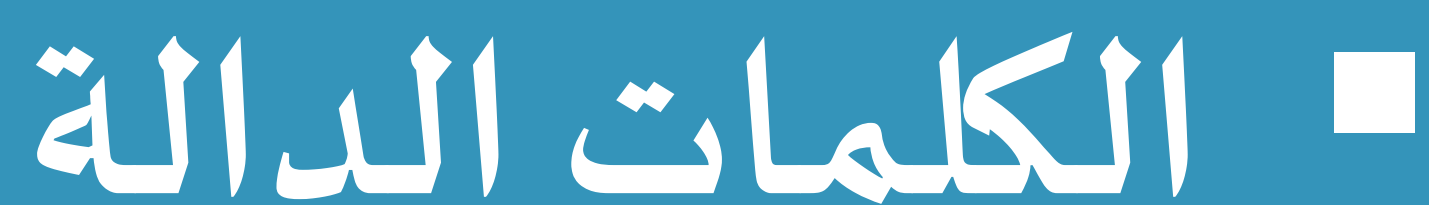
التصيورات الاجتماعية، الثقافة، الشخصياة، كأس العالم، قطر. بجربة العبئ في فطر

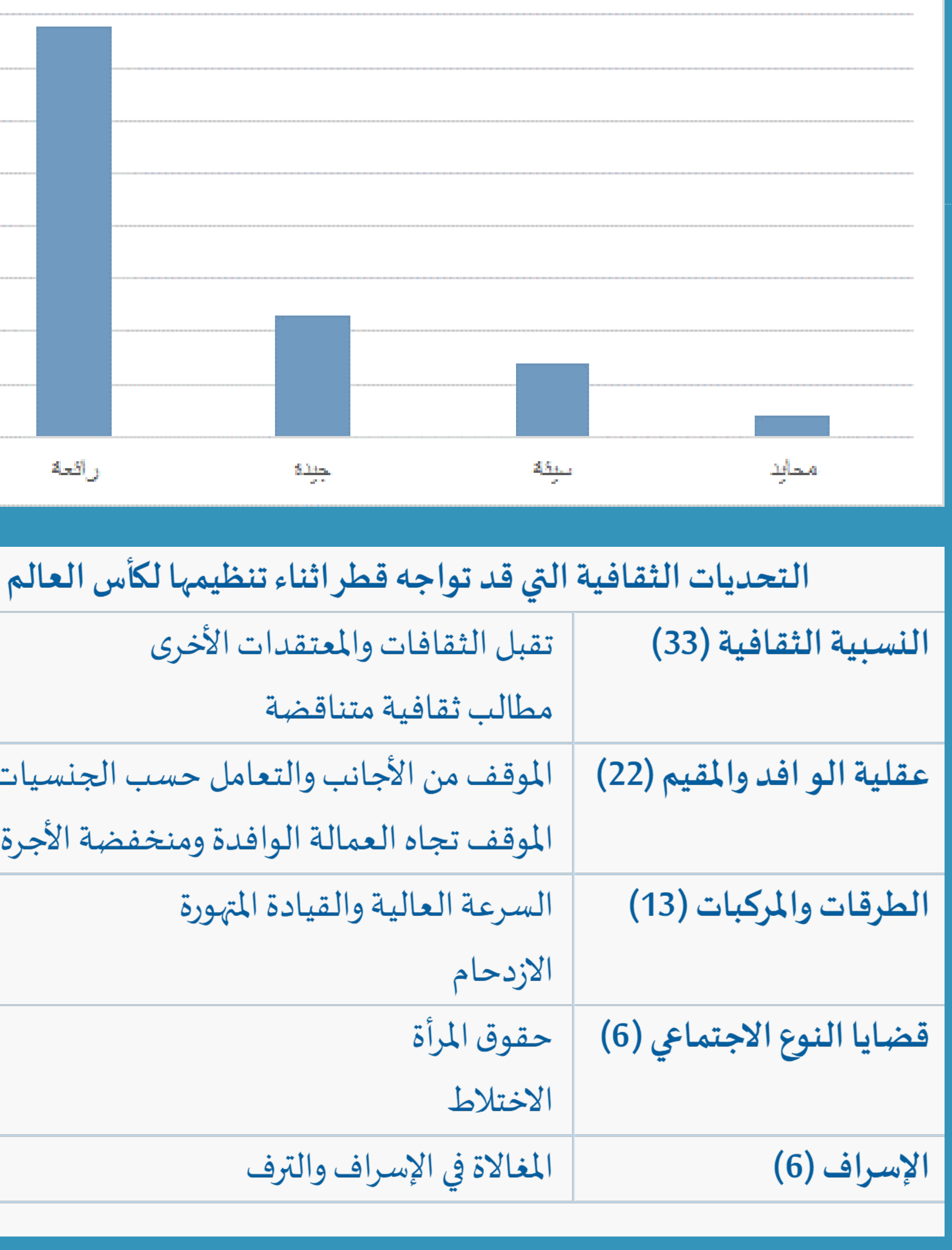

تتمتع دولة قطر بإمكانيات إضافية في مجال القوة الناعمة، باعتبارها من الدول التي تستقطب أعداداً كبيرة من المقيمين من خلفيات ثقافية متنوعة، يمكنهم المساهماة في تعزيز جهودها في صنع صورة الدولة وترويجها، في إطار استعدادها لتنظيم كأس العالم 2022. تهدف هذه الدراسة إلى الإجابة على التساؤلات التالية: • ما تصورات المقيمين في دولة قطر عن دولة قطر قبل قدومهم إليها وبعد إقامتهم فيها؟ • ما تصورات المقيمين في دولة قطر عن المجتمع القطري وثقافته؟

• كيف يتصور المقيمون في دولة قطر الشخصيية القطرية؟

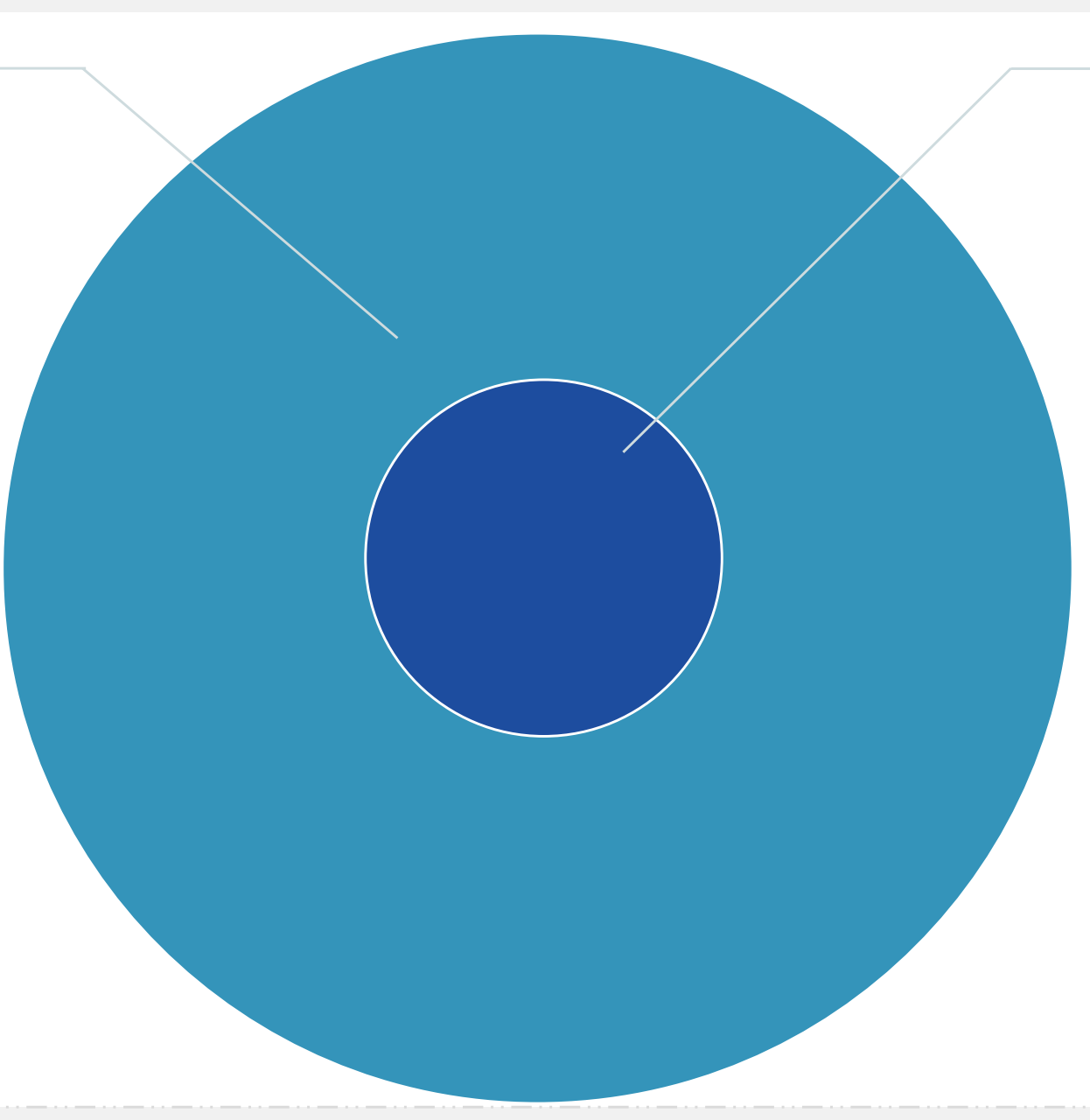

النواة المركزية

- مرتبط بالذاكرة الجماعية وتاريخ الجماعبة

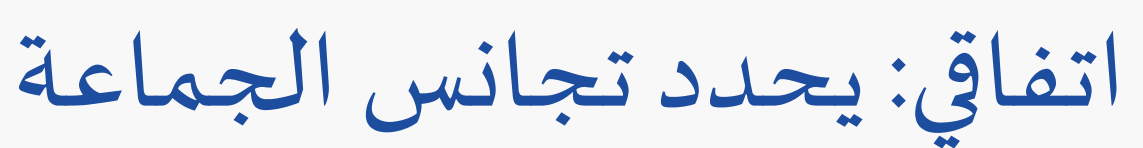

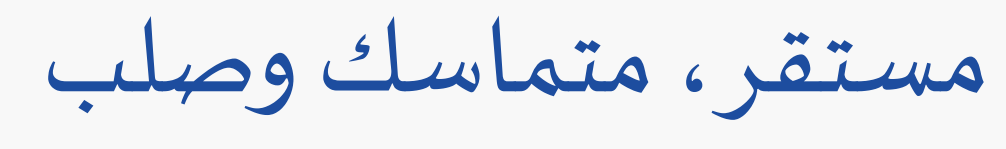

| بليل الحساسية للإطار المباشر
النسق المحيطي

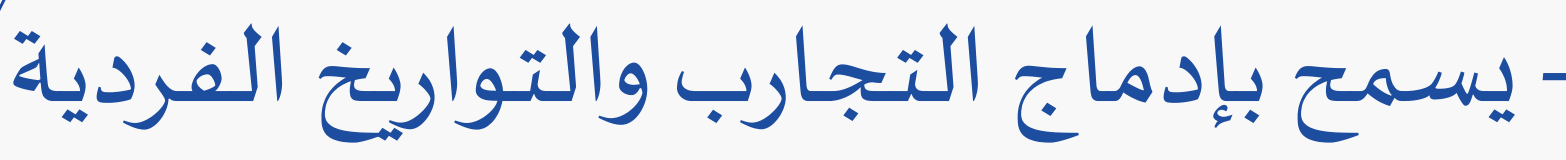

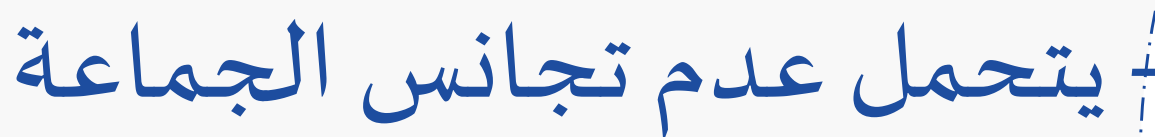

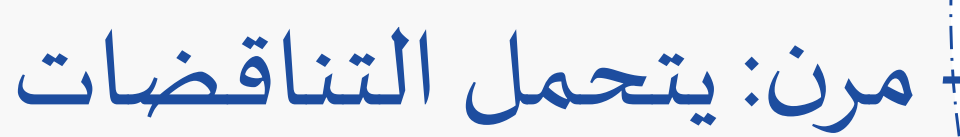

(- متطور

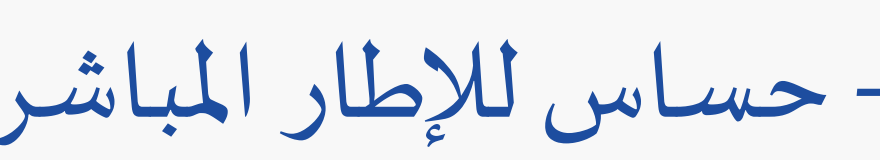

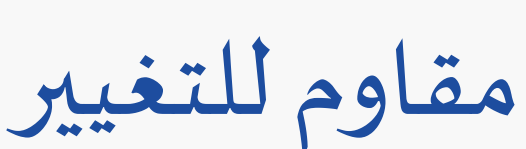

\section{أهمية الدراسـة}

تعالج الدراسة موضوعا تندر حوله المرجعيات العلمية التي تحتاجها دولة قطر في سياق استعدادها لتنظيم كأس العالم 2022 تعتبر هذه أول دراسة نوعية تتناول تصورات المقيمين في دولة قطر، وستساهم في رفد المكتبة العلمية بمرجع علمي موثوق في الموضوع، وتساهم في دعم صناع القرار في رسم سياساتهم في القضايا المدروسة.

أداة حمع البيانات: أجريت مقابلات (Online Asynchronous Interviews) من خلال التطبيق الحاسوبي (Survey Monkey)، باللغتين العربية والإنجليزية.

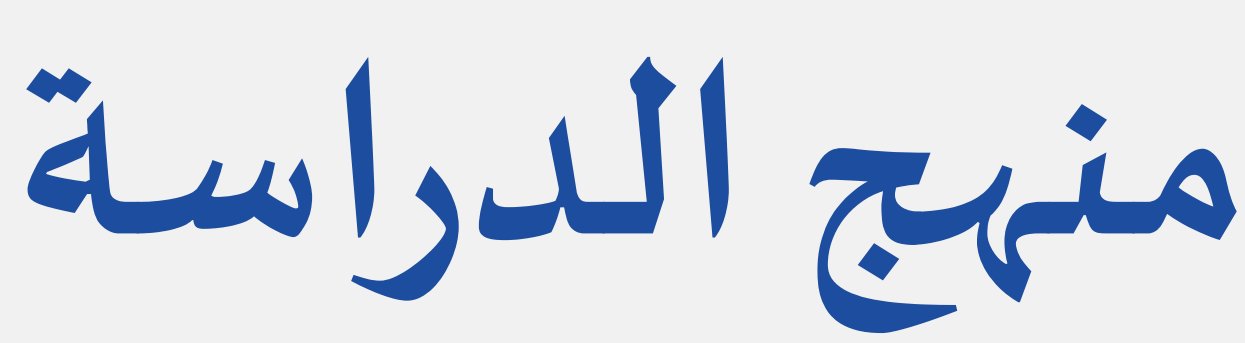

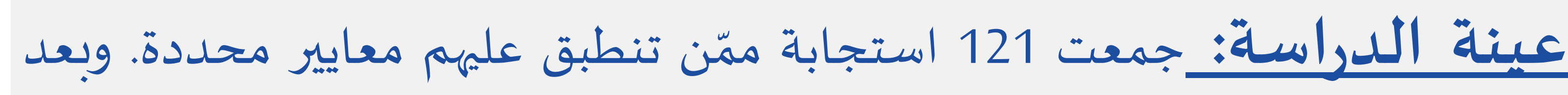

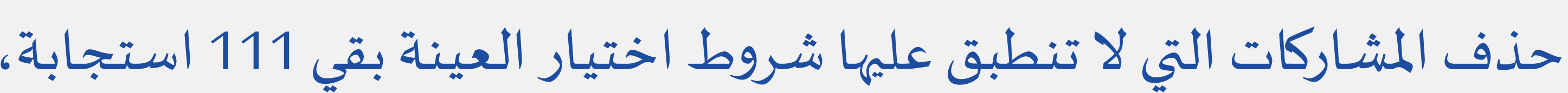
تحليل البيانات: تم تحليل إجابات المشاركين باللغتين العبية والإنجليزية تحليلا

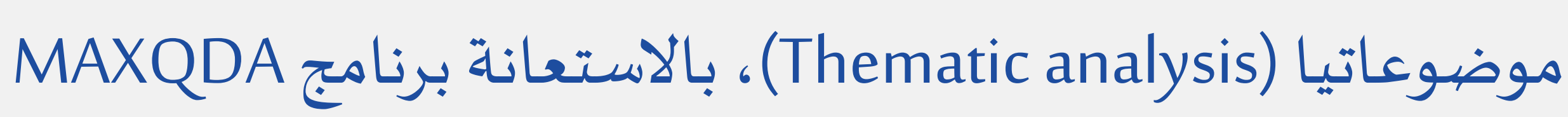

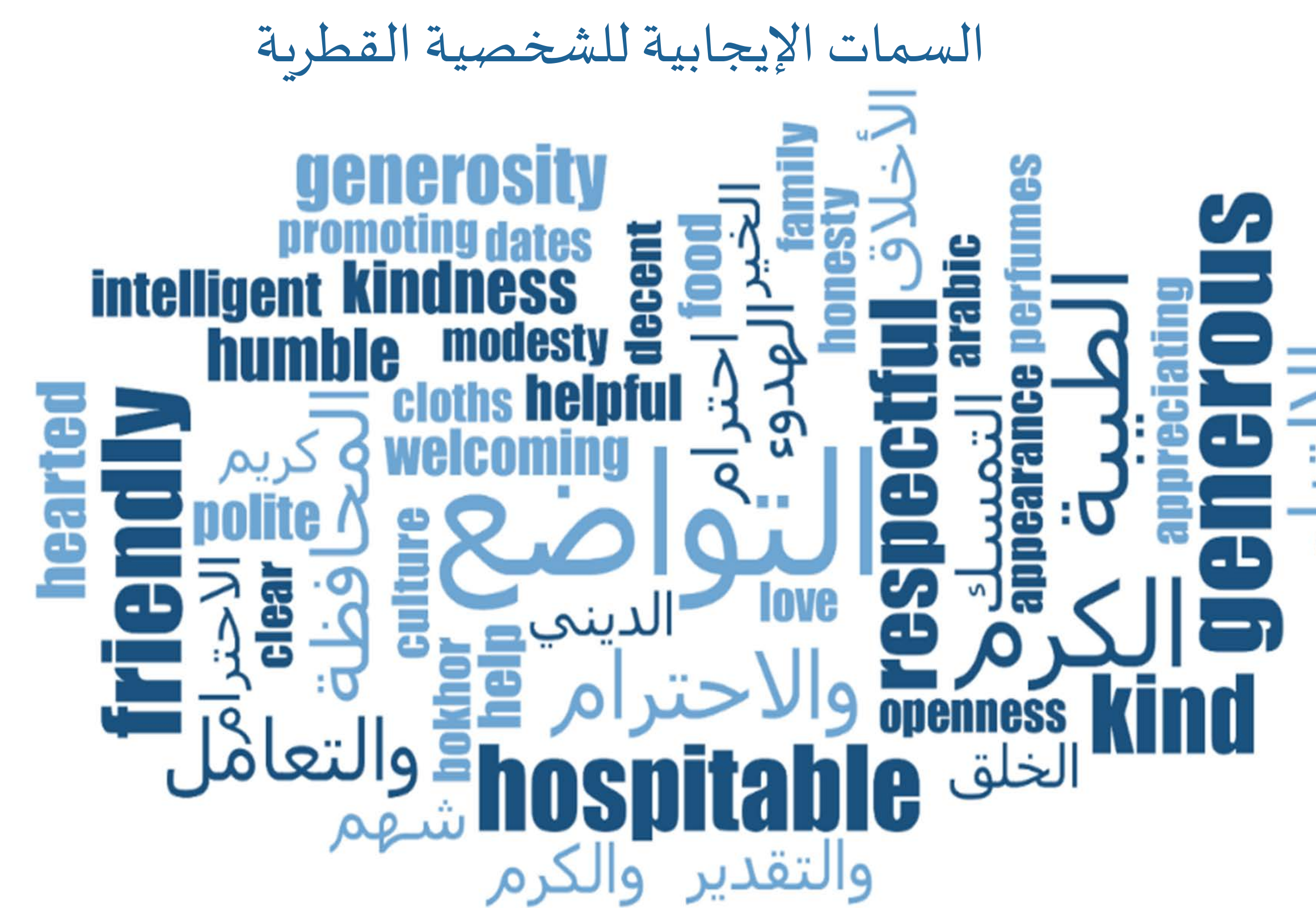

نصورات المقيمين تجاه السمات الإبجابية للشخصبة القطرية

\begin{tabular}{|c|c|c|}
\hline 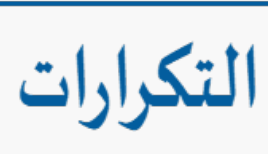 & 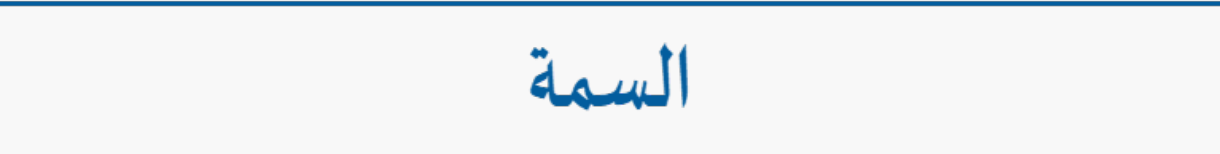 & السمات الشخصية \\
\hline 94 & الكرم، والتواضع، والطيبة، والثهامة، والهدوء، والأحترام، والأدب، والرقي، واللباقة & البعد الأخلاقي \\
\hline 14 & التدين، والمحافظة، والعروبة، والاعتزاز بالثقافة & البعد الثقافي \\
\hline 9 & مساعدة الآخرين، وحب الخير & البعد التواصلي \\
\hline 8 & الثقافة، والعلم، وحب المعرفة & البعد المعرفي \\
\hline 8 & حب الوطن، والثبات في الأزمات & البعد الوطني \\
\hline 7 & حسن المظهر والهندام، والنظافة & البعد المظهري \\
\hline
\end{tabular}

اخترنا منهجا نوعيا يمكّن من الوصول إلى ما

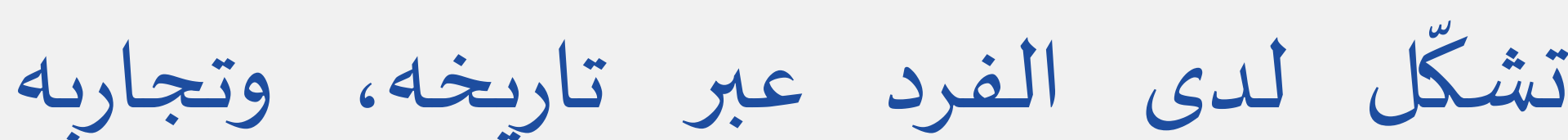
الذاتية، من تصورات وأفكار وصهور ذهنية تارية وتجارنية

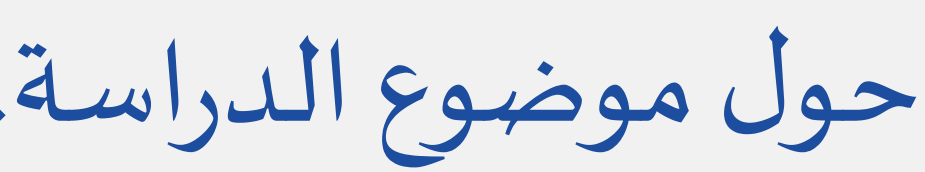

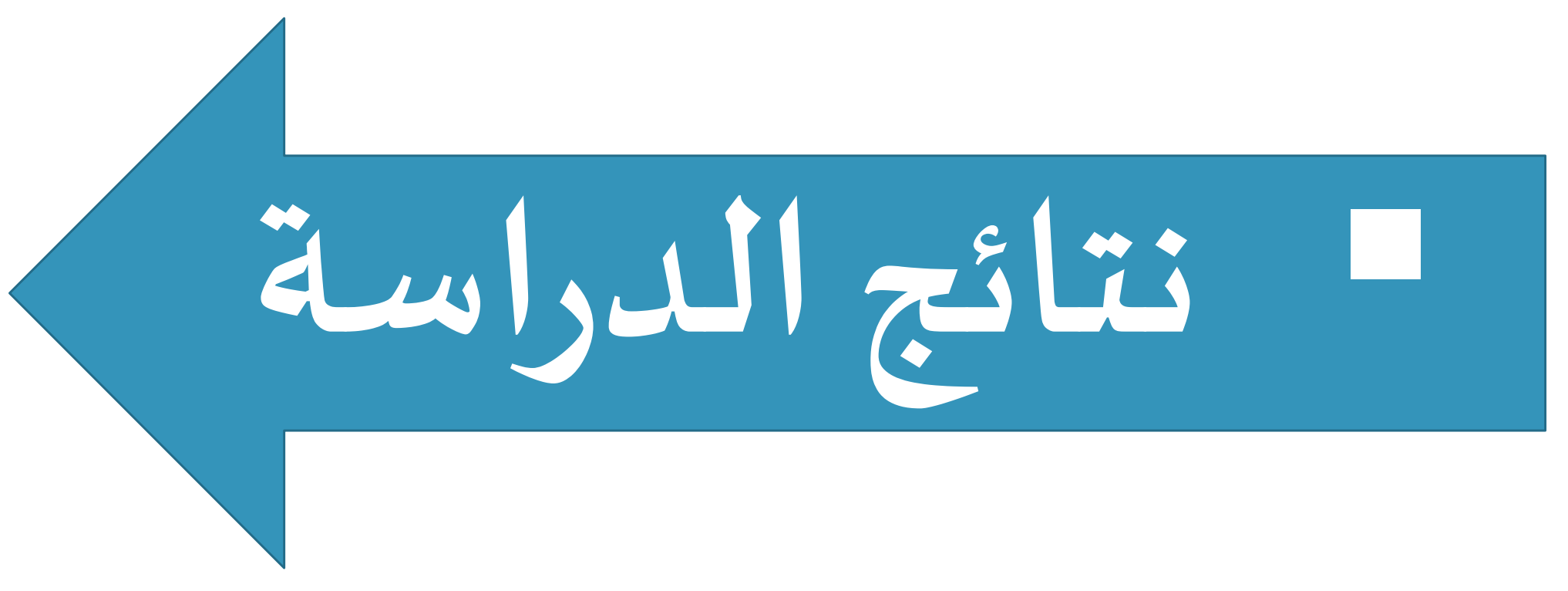

الانطباعات الأولى عن دولة قطر organized parts 1920 1 Clean DC I I d develop deserted

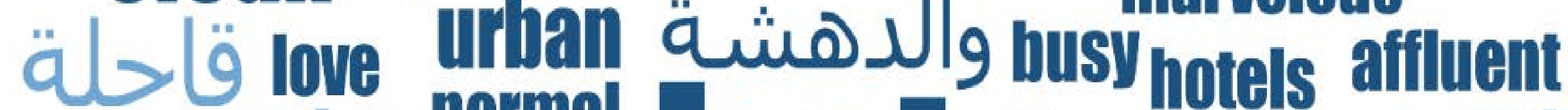
amazing normal

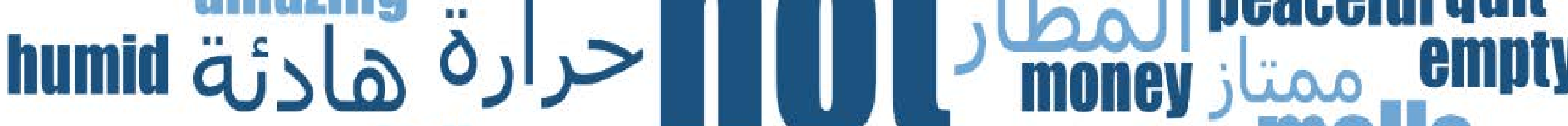
ua facilities calm luxiouris impressive حيد " great cozy الإسلامية dailly boring

äuas expensive ideal decent hell hotter construction luxuries IIta|s الإعحان greenery

\section{خاتمة وتوصيات}

تلعب تصيورات الجمههور الداخلي في الدول ذات التهات التنوع الثقافي كبير دوراً كبيراً في سمعة الدولة داخليا وخارجيا. الأمر الذي يتطلب تفعيل أدوات التفاعل الثقافي البيني غير الهادف إلى

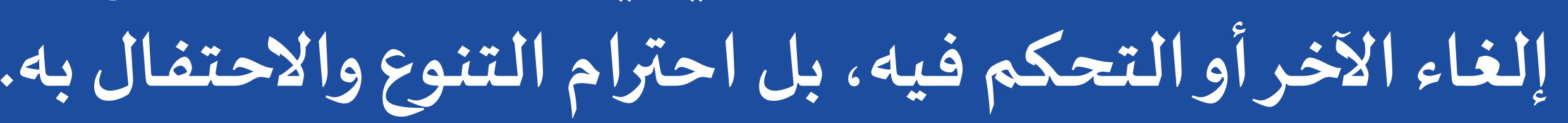
التصيّورات الجماعية التي تتشكل بعيدا عن موضيوع التصهورزمانا ومكانا يكون عرضهة للتشويه، فتصهورقطرفي التخارج يختلف عنه في الداخل، وتصيورقطرقبل الإقامة بها تختلف عن تصورها بعد الإقامة بها. توصي الدراسة الجهات المسؤولة عن صناعة ونشر صهورة قطر الاهتمام بتصهورات المقيمين في الدولة، كونهم يلعبون دروا كبيرا في تشكيلها ونشرها.

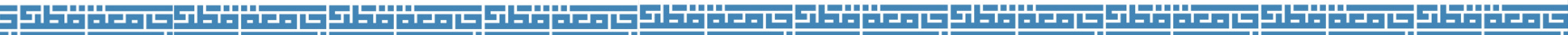

